Delft University of Technology

\title{
SAG foam flooding in carbonate rocks
}

\author{
Boeije, C. S.; Rossen, W. R.
}

DOI

10.1016/j.petrol.2018.08.017

Publication date

2018

Document Version

Final published version

Published in

Journal of Petroleum Science and Engineering

\section{Citation (APA)}

Boeije, C. S., \& Rossen, W. R. (2018). SAG foam flooding in carbonate rocks. Journal of Petroleum Science and Engineering, 171, 843-853. https://doi.org/10.1016/j.petrol.2018.08.017

\section{Important note}

To cite this publication, please use the final published version (if applicable).

Please check the document version above.

Other than for strictly personal use, it is not permitted to download, forward or distribute the text or part of it, without the consent of the author(s) and/or copyright holder(s), unless the work is under an open content license such as Creative Commons.

\section{Takedown policy}

Please contact us and provide details if you believe this document breaches copyrights.

We will remove access to the work immediately and investigate your claim. 


\title{
SAG foam flooding in carbonate rocks
}

\author{
C.S. Boeije*, W.R. Rossen \\ Department of Geoscience and Engineering, Delft University of Technology, Netherlands
}

\section{A R T I C L E I N F O}

\section{Keywords:}

Foam

EOR

SAG

Core flooding

\begin{abstract}
A B S T R A C T
Foam is used in gas-injection EOR processes to reduce the mobility of gas, resulting in greater volumetric sweep. SAG (Surfactant Alternating Gas) is a preferred method of injection as it results in greater injectivity in the field, but designing a successful process requires knowledge of foaming performance at very high foam qualities (gas fractional flows).

Here the use of foam in low-permeability $(\sim 1 \mathrm{mD})$ Indiana Limestone cores for SAG foam applications is studied. Coreflood experiments were performed for a range of foam qualities at high pressure (100 bar), elevated temperature $\left(55^{\circ} \mathrm{C}\right)$, high salinity $(200,000 \mathrm{ppm})$ and in the presence of crude oil. The effectiveness of the foam was studied by differential pressure measurements along the core. Foam was still able to form under these stringent conditions, but it was a relatively weak foam (i.e. its ability to reduce gas mobility is modest). For one surfactant formulation, further analysis of the experimental results show that the foam would be able to maintain mobility control over the displaced phase, thus providing a stable displacement front, and that it can be used in a SAG foam process in these formations. For a second formulation the non-monotonic nature of the fractional-flow data requires further investigation before scale-up to the field.

In addition, further coreflood experiments were carried out using heterogeneous, vuggy Edwards White cores with even lower permeability $(\sim 0.5 \mathrm{mD})$. These experiments were performed to determine whether foaming is possible in heterogeneous media and especially to investigate the effects of disconnected vugs on the foaming performance. CT scans were taken during the period of foam injection to determine saturation profiles within the core. Foam was able to form inside these cores, but inside the vugs segregation was observed with liquid pockets visible in the bottom of the vugs and gas in the remainder. This segregation was only a local effect though, confined to the vug itself, and foam was able to persist in the rest of the core.
\end{abstract}

\section{Introduction}

A common method of improving oil recovery from a reservoir is through the injection of gas in order to displace oil and maintain pressure. The main problem with gas injection is that it suffers from poor sweep efficiency. Reasons for this include viscous fingering (due to the mobility contrast between the injected gas and the displaced phase), channeling (gas prefers to flow through high-permeability layers, thus low-permeability layers remain unswept) and gravity override (the injected gas has a lower density than the oil in place, therefore flowing to the top of the reservoir, causing an unswept lower region in the reservoir, (Lake et al. (Lake et al., 2014))). Foam can help alleviate these problems by trapping the gas in bubbles, thereby reducing its mobility. This results in a more stable displacement front and thus an increase in volumetric sweep (Schramm (1994); Rossen (Rossen, 1996)).

In this study we focus on the application of foam in SAG injection in carbonate formations. These rocks pose some specific challenges which need to be overcome in order for foam to be an effective method of enhancing oil recovery. One of the main problems with carbonate reservoirs is that they typically have low permeability compared to sandstone reservoirs. Ehrenberg and Nadeau (2005) provide average values of porosity and permeability for over 40,000 reservoirs worldwide. As shown in Fig. 1a and b, they find that carbonates on average have a significantly lower porosity than sandstone reservoirs, and a lower average permeability as well. The effectiveness of foam in controlling gas mobility is greater in higher-permeability media, as was first identified by Bernard and Holm (1964). Other studies, including Falls et al. (Falls et al., 1988); Khatib et al. (Khatib et al., 1988) and Moradi-Araghi et al. (Moradi-Araghi et al., 1997) also find reduced effectiveness of foam in lower-permeability media. Still, Szlendak, et al. (Szlendak et al., 2012) found that in-situ foaming enabled mobility control in tight $(\approx 10 \mathrm{mD})$ formations.

Foam has been studied extensively in heterogeneous rocks. When it comes to large-scale heterogeneities, such as layered reservoirs, foam

\footnotetext{
* Corresponding author.

E-mail address: christian.boeije@enise.fr (C.S. Boeije).
} 


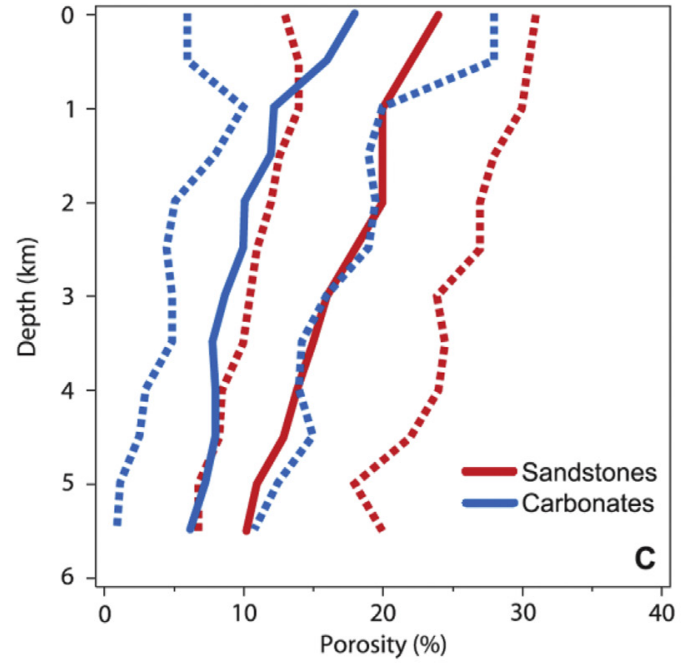

(a)

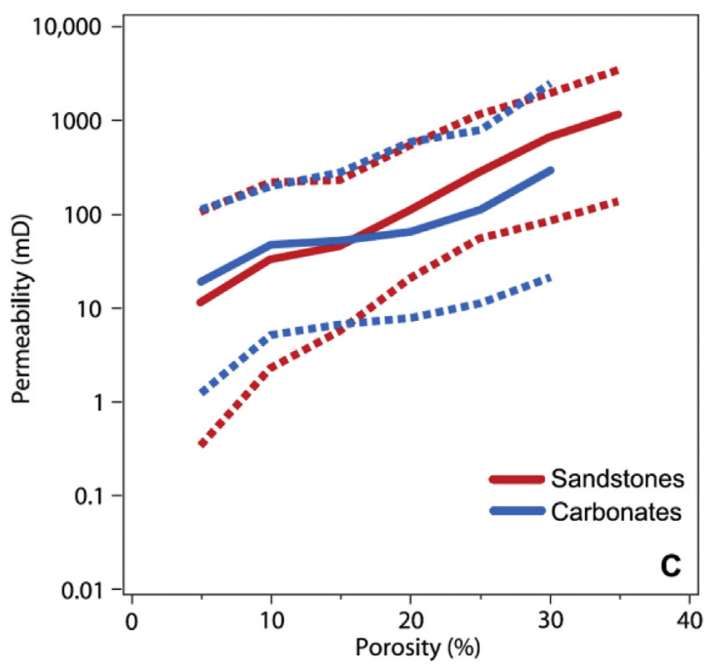

(b)

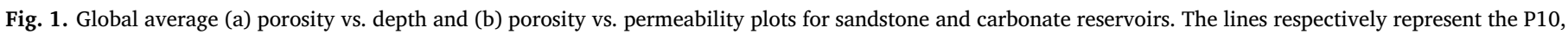
P50 and P90 values (from (Ehrenberg and Nadeau, 2005)).

injection is often considered as an enhanced oil recovery method. This is because foam often reduces the mobility more in high-than in lowpermeability zones.

Another complication in carbonate formations is existence of vugs: i.e., large voids (much larger than pores). Vugs could act as stagnant zones where foam segregates and breaks, as in foam half-life tests in the laboratory. On the other hand, Fernø, et al. (Fernø et al., 2015) showed foam generation during flow into vugs in fracture networks. Interconnected vugs pose a special challenge for foam. Here we consider isolated vugs. Other complications in carbonates, not examined here, include adverse wettability and natural fractures. Boeije et al. (Boeije et al., 2017) proposed a screening protocol to identify surfactants capable of foaming in oil-wet porous media.

Here we study foam in a low-permeability carbonate rock. Our main set of foam-flood experiments are performed at high pressure (100 bar back-pressure), elevated temperature $\left(55^{\circ} \mathrm{C}\right)$ and high salinity $(200,000 \mathrm{ppm})$. Initially we focus on tests without the presence of crude oil. Foam behaviour at high foam qualities (gas fractional flow) is of special interest, to show whether the foam is suitable for a SAG injection process (Shan and Rossen (2004); Rossen and Bruining (2007)). Rossen and Boeije (2015) show that it is crucial to know the behaviour at high foam quality in order to determine whether a SAG process can be successful. A complete description of a SAG process would require also investigation of liquid-slug injectivity and foam properties further from the well, where slugs mix. Afterwards we perform experiments with crude oil added to the co-injected fluids to assess its influence on foaming performance. Another experiment is aimed at determining the influence of rock heterogeneity and vugs on foaming performance. This experiment is carried out using a heterogeneous, vuggy carbonate core placed inside a CT scanner.

\section{Experimental setup and procedure}

The setup used for the main set of foam-flooding experiments consists of the following components. The porous medium that is used is a 40-cm-long, 4-cm-diameter consolidated Indiana limestone core in a PEEK core holder. The operating conditions in all of these experiments is the same ( 100 bar back-pressure, $55^{\circ} \mathrm{C}$ and $200,000 \mathrm{ppm}$ salinity). The core holder is mounted vertically in a Tamson TV7000 thermo bath which is used to maintain the desired temperature of $55^{\circ} \mathrm{C}$ inside the porous medium. The setup allows for co-injection of gas, surfactant solution and oil. The gas phase in these experiments is methane $\left(\mathrm{CH}_{4}\right)$, which is injected using a Bronkhorst EL-FLOW F230M mass flow controller. A Quizix QX-6000 low-flow-rate pump is used to inject the aqueous phase. In some of the experiments described here, crude oil $\left(32^{\circ} \mathrm{API}\right)$ was also injected along with the other fluids using a Gilson 305 Piston Pump along with a transfer vessel. Dresser Mity-Mite Model 91 gas-loaded back-pressure regulators were installed to maintain the system at the desired operating pressure. To analyze the pressure inside the core, four differential pressure transducers (Endress + Hauser Deltabar S PMD75, range 0-3 bar) were installed to measure pressure drops within different sections of the core. In addition, another differential pressure transducer (Endress + Hauser Deltabar S PMD75, range 0-40 bar) was installed to measure the pressure drop over the entire core. Absolute pressure transmitters were installed up- and downstream of the core to monitor absolute pressure in the system; they can also be used to check whether the differential pressure measurements are correct. In all of the experiments described here, the flow direction is from the bottom of the core to the top. An overview of the setup used for this set of experiments is given in Fig. 2.

Note that the presence of crude oil inside the core in some experiments does not mean that reservoir conditions are mimicked perfectly. For that, other attributes such as the core's wettability needs to be altered as well by aging the core. Other aspects such as the pore size distribution and permeability of the rock are correctly represented in these experiments. The reason oil is injected along with the other fluids is that we aim to show the foam's behaviour in the presence of oil at steady state. This cannot be attained by performing oil recovery experiments from as there is no steady state in such experiments. The goal of these experiments is not to fully represent reservoir conditions and perform oil recovery experiments. Lab experiments using foam injection tend to result in excessive pressure gradients which are not feasible on the field scale and as such, do not yield representative recovery factor values.

Experiments were performed with two different surfactants at a salinity of $200,000 \mathrm{ppm}$. The surfactants were chosen based on their foaming performance as described in Boeije et al. (Boeije et al., 2017). We selected a non-ionic alkylpolyglycoside (hereinafter APG) and an anionic alcohol ethoxy sulphate (hereinafter AES), at a concentration of $0.5 \mathrm{wt} / \mathrm{wt} . \%$ active content. The brine composition is given in Table 1 .

In addition, another foam-flooding experiment was performed with a shorter, $17 \mathrm{~cm}$ long, carbonate core inside a CT scanner (Siemens, 3rd generation). The core was mounted vertically inside the opening of the CT scanner. This limits the size of the core that can be used. The rock 


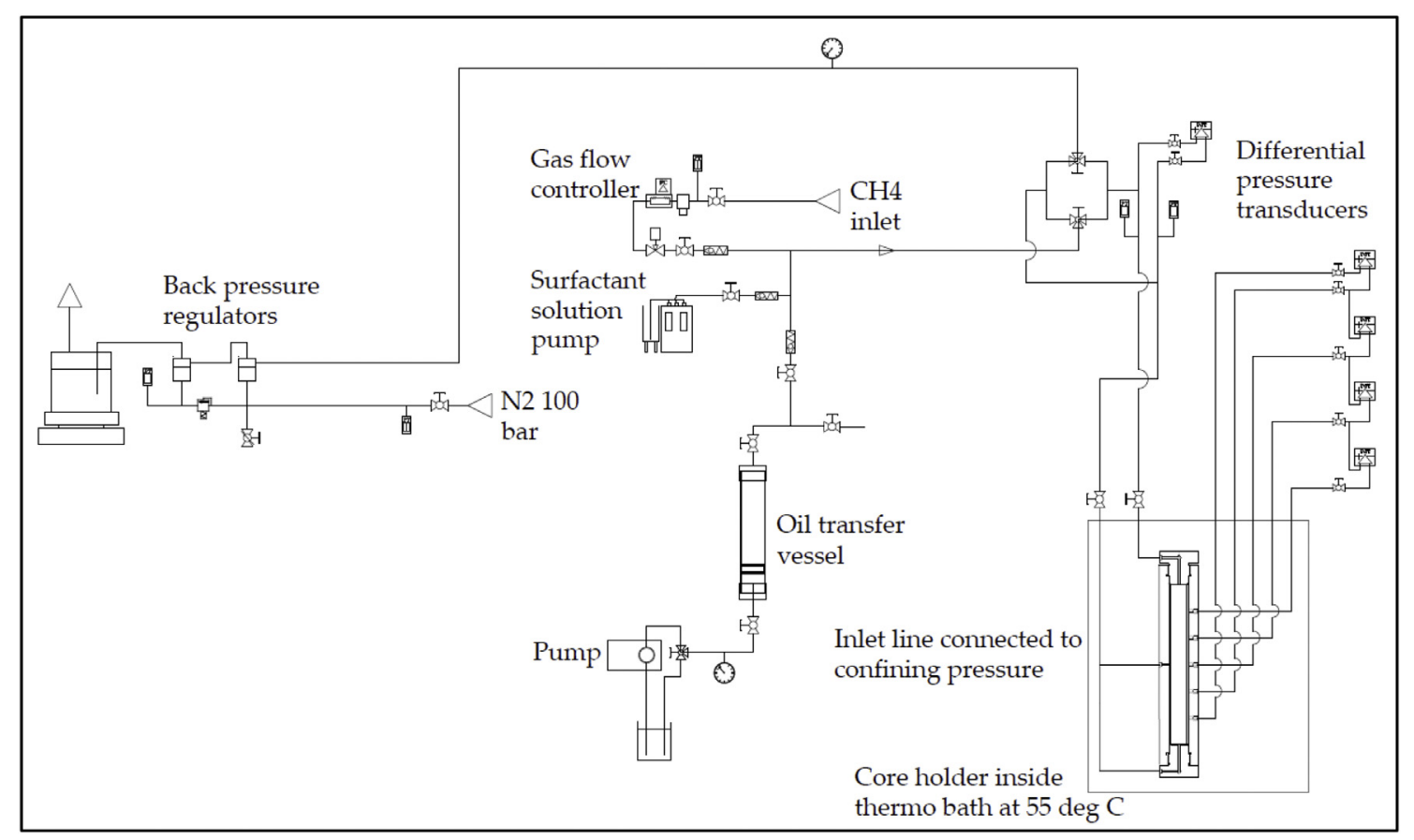

Fig. 2. Schematic overview of setup used in long-core experiments.

Table 1

Brine composition for 200,000 ppm brine.

\begin{tabular}{ll}
\hline Ion & Concentration [ppm] \\
\hline $\mathrm{Cl}^{-}$ & 122,500 \\
$\mathrm{Na}^{+}$ & 55,900 \\
$\mathrm{Ca}^{2+}$ & 19,500 \\
$\mathrm{~K}^{+}$ & 2100 \\
\hline
\end{tabular}

used in this experiment was Edwards White, which is a heterogeneous, vuggy carbonate. These experiments were performed to determine the fluid saturations within the core, and in particular to test whether the high level of heterogeneity of the cores, in combination with their vuggy nature, has a significant impact on the foaming performance. We were not trying to mimic specific reservoir conditions in these CT experiments, but rather to probe foam behaviour in general. Therefore we performed the experiments at room temperature using zero-salinity solutions. For safety reasons we made use of nitrogen gas for the CT experiments rather than the methane that is used in the other experiments in this study. The back-pressure was kept at 100 bar (i.e. the same as the other experiments) to avoid significant effects of compressibility. The surfactant used for this experiment was the non-ionic alkylpolyglycoside (APG) that was also used in the longer-core, Indiana limestone foam floods. A schematic of this experimental setup is given in Fig. 3.

Two differential pressure transducers were installed to measure the pressure drop over the entire core and the middle segment of the core, respectively. In addition, two absolute-pressure transducers were used to monitor the pressure at the outlet of the core and at the end of the middle segment. In this way, the pressure in each segment could be monitored separately.

\subsection{Procedure}

Procedures for both the long-core and the CT experiments were similar: Foam-flooding experiments are carried out using co-injection of gas and surfactant solution ( $0.5 \mathrm{wt} / \mathrm{wt} . \%$ active content). The pressure drop over the core is monitored during the experiment. The heterogeneity in the core in terms of permeability is also assessed by monitoring and comparing pressure drop in the different sections of the core. For the long-core experiments, the main goal is to perform steadystate foam floods at varying foam qualities. This will result in a plot of $f_{g}$ vs. $\nabla p$ similar to those from various studies (e.g. Ma et al. (Ma et al., 2013) and Kapetas et al. (Kapetas et al., 2016)). We are especially interested in foam behaviour at very high foam qualities, because this is crucial for predicting the mobility during the gas injection in a SAGinjection process (cf. Rossen and Boeije (2015)). Thus we focus our experiments at foam qualities larger than 0.5 , up to foam quality 0.99 . We aim to construct fractional-flow curves based on experimental results. To determine foam effectiveness at the leading edges of the gas slug, one must find the point of tangency to the fractional-flow curve and the mobility at that point, which corresponds to the mobility of the

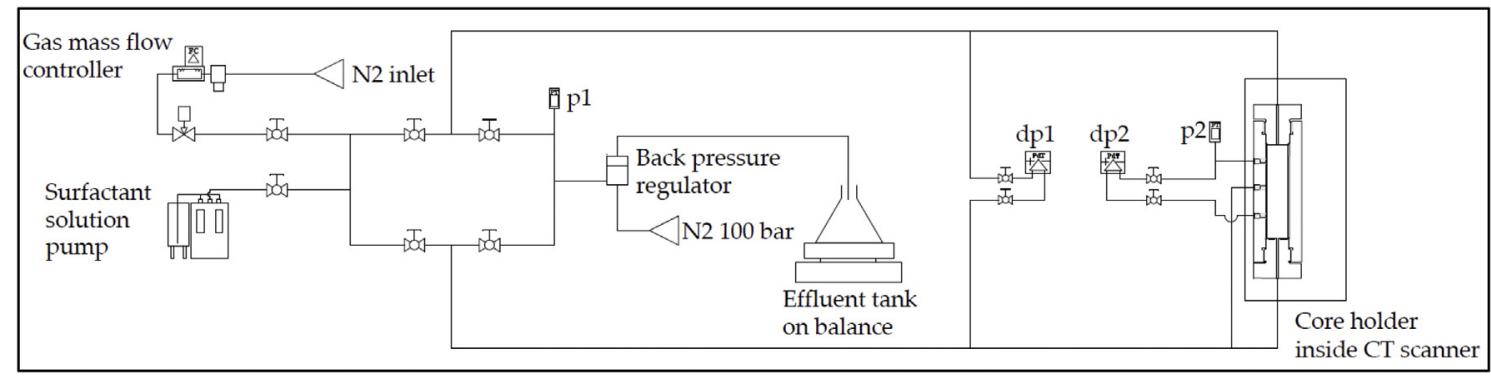

Fig. 3. Schematic overview of setup used in CT visualization experiments. 
foam front in a gas injection cycle of a SAG process ${ }^{14}$.

Because we focus on behaviour in the high-quality regime, we do not expect strongly shear-thinning behaviour and make use of the version of the STARS foam model (Computer Modeling Group, 2006) that incorporates only the water-saturation-dependent function $F_{2}$. Thus we use the following functional form of the foam model:

$F M=\frac{1}{1+f m m o b \cdot F_{2}}$

where fmmob is a reference mobility reduction factor and the function $\mathrm{F} 2$ is defined as:

$F_{2}=0.5+\frac{\arctan \left(\text { epdry } \cdot\left(S_{w}-f m d r y\right)\right)}{\pi}$

For the CT experiment, too, we run the experiment until a steady state is reached. In addition to the overall steady-state pressure response we also observe the distribution of water saturation inside the porous medium. Especially we focus on the behaviour inside and around the vugs, as these are fairly large in size relative to the dimensions of the core, and may have significant impact on the development of foam.

\section{Results and discussion}

\subsection{Results from long-core experiments}

Before starting foam injection, we measured the steady-state pressure gradient in single-phase water flow for different flow rates in order to measure the liquid permeability. The core is fairly homogeneous and has a permeability of $1.01 \mathrm{mD}$. In a separate test, the porosity of small (3.5 cm length, $3.1 \mathrm{~cm}$ diameter) core plugs of the same rock was measured using a Quantachrome Ultrapycnometer 1000 which measures the pore volume of the sample. In total the porosity of 11 core plugs was measured and the average porosity was found to be 0.13 .

The main results from the experiments performed using the long Indiana Limestone cores are pressure-drop measurements aimed at determining foam's ability to reduce total mobility. As mentioned above, the mobility of the foam at the front during gas injection in a SAG-foam process is defined by a point of tangency to the fractionalflow curve. Results presented here are mainly steady-state pressure gradient over the mid-section of the core, excluding the entrance and exit regions. The foaming performance in the entry and exit regions of the core may not be representative of the overall foaming performance and are thus neglected. For the long-core experiments this means we use the cumulative pressure difference as measured by the four internal pressure transducers.

The results are pressure-gradient measurements at varying foam qualities, but at fixed total superficial velocity, focused primarily on the high-quality regime. We can fit the STARS parameter values using the method outlined in Rossen and Boeije (2015). For the first experiment, we check whether the entrance and exit regions of the core significantly affect the foaming performance by comparing the pressure gradient over the entire core to that in the middle section. Fig. 4a shows the pressure-gradient data for the experiment using the APG surfactant and an initial straight-line estimate as a fit. Fig. 4b shows the result from the same experiment for the internal section of the core (i.e. the total core except for the entrance and exit regions). The pressure gradient in the latter plot is approximately $25 \%$ higher than the result including the entry and exit regions. The section of the core across which the pressure difference was measured is $67 \%$ of the total length of the core (26.8 vs. $40 \mathrm{~cm}$ ) and the pressure drop measured in that section varied from 80 to $85 \%$ of the total pressure drop.

Probably most of the difference reflects an "entrance region" of no foam in the first section (Ettinger and Radke (1992); Ransohoff and Radke (1988)). We only use the pressure result from the mid-section of the core for the remainder of the analysis presented here. The total superficial velocity is kept constant in these measurements at $0.05 \mathrm{ml} /$ $\mathrm{min}$, which for a 4 -cm-diameter core is equivalent to $6.63 \cdot 10^{-7} \mathrm{~m} / \mathrm{s}$ $(0.188 \mathrm{ft} /$ day).

All of the experimental data appear to be in the high-quality regime, which is indicated by the fact that with increasing foam quality $f_{g}$, the pressure gradient decreases (Alvarez et al., 2001). A straight line provides a first-estimate fit through the data-points. This rough fit to the straight-line trend also implies that the water relative permeability remains fairly constant here. We can use this to estimate the limiting water saturation $S_{w}{ }^{*}$, which corresponds to the STARS model parameter fmdry. We can determine the water relative permeability in the highquality regime by rewriting Darcy's law as follows:

$k_{r w}\left(S_{w}^{*}\right)=\frac{u_{t} \mu_{w}\left(1-f_{g}\right)}{k \nabla p}$

where $f_{g}$ and $\nabla p$ are obtained from the straight-line fit through the data (cf. Boeije and Rossen (2015a)). For this data-set the value of $k_{r w}\left(S_{w}{ }^{*}\right)$ is $5.0 \cdot 10^{-2}$. To accurately determine the value of fmdry, suitable gas and water relative-permeability functions are needed. Mohamed and NasrEl-Din (Mohamed and Nasr-El-Din, 2012) provide relative-permeability curves for several carbonate rocks, including low-permeability Indiana Limestone. We fit a Brooks-Corey-type relative-permeability function to their data with the following result:

$k_{r w}=0.28\left(\frac{S_{w}-0.32}{1-0.32-0.08}\right)^{2.41}$

$k_{r g}=0.05\left(\frac{1-S_{w}-0.08}{1-0.32-0.08}\right)^{1.02}$

The value of $S_{w}{ }^{*}$ (or fmdry) can be determined by rewriting Eq. (3) into an expression for the saturation and using the aforementioned value of $k_{r w}\left(S_{w}{ }^{*}\right)$. During the experiments, fluctuations of about $\pm 10 \%$ around the steady-state pressure gradient for each injection condition were observed. These fluctuations correspond to a difference in the inferred values of $S_{w}$ of about \pm 0.01 . The resulting estimate of fmdry is $0.59 \pm 0.01$.

Accurately determining the value of fmmob requires knowing the foam quality at the point of transition between the low- and highquality regime $\left(f_{g}^{*}\right)$ (cf. Boeije and Rossen (2015a)). In this experiment, all the data are in the high-quality regime, so there is no transition point in the data. This means that the values of $f_{g}{ }^{*}$ and $f m m o b$ cannot be determined. This is not a problem in this case since we are interested only in the mobility at the gas front in a SAG process. As discussed in Rossen and Boeije (2015) the mobility at the gas front is determined by the point of tangency to the fractional-flow curve, which for a foam flood is in the high-quality regime. To determine the point of tangency, first we need to determine the liquid saturations for all data points. We can then use the saturations to estimate the fractional-flow curve. The saturation can be estimated in the same way we determined $S_{w}{ }^{*}$, using the Darcy's law for the water phase along with the known relativepermeability function $k_{r w}$.

The shock line is a straight line from the point of tangency to the initial condition (which in this case is at $S_{w}=1$ ). The resulting fractional-flow curve fit to the data, using the approach of Rossen and Boeije (2015), along with the shock line from the point of tangency, is shown in Fig. 5a. A detailed view of the same fractional-flow curve around the point of tangency is shown Fig. $5 b$, from which we can see that the water saturation at the point of tangency is 0.581 .

We then use the water saturation to determine the total mobility at the leading edge of the foam bank using Eq. (5) and compare it to the mobility of the displaced phase (in this case water):

$\lambda_{r t}\left(S_{w}^{t}\right)=\lambda_{r w}+\lambda_{r g}=\frac{k_{r w}\left(S_{w}^{t}\right)}{\mu_{w}}+\frac{k_{r g}\left(S_{w}^{t}\right) \cdot F M\left(S_{w}^{t}\right)}{\mu_{g}}$

where $S_{w}{ }^{t}$ is the water saturation at the point of tangency to the 


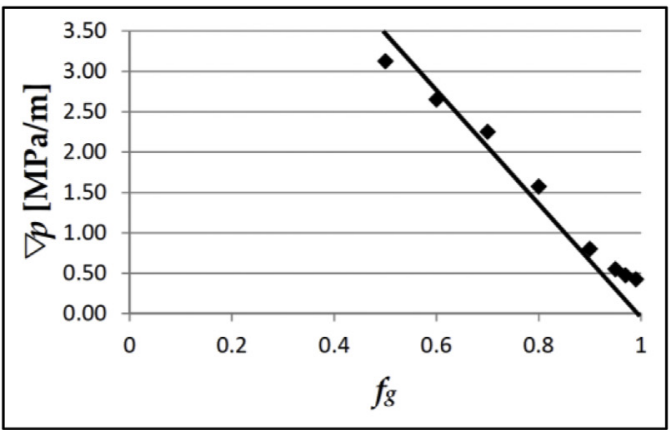

(a)

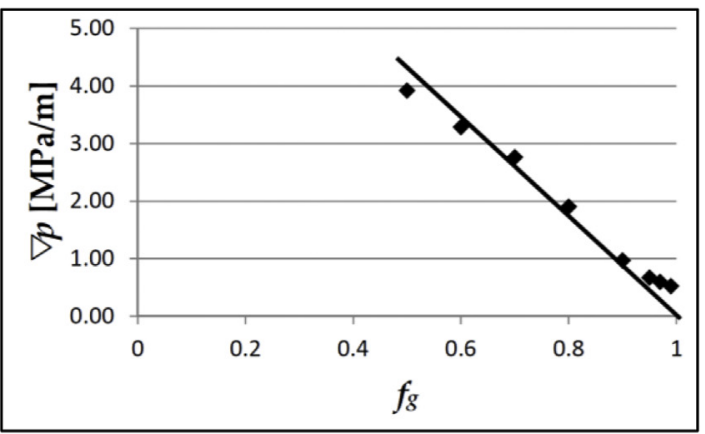

(b)

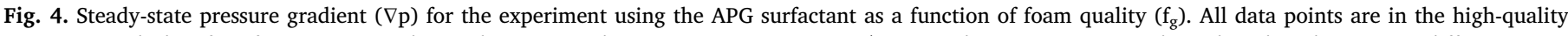

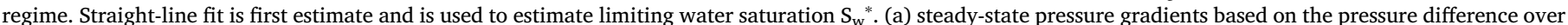
the entire core (b) results without entry and exit regions.

fractional-flow curve. For the experiment using the APG surfactant, the resulting value of $\lambda_{r t}\left(S_{w}{ }^{t}\right)$ is equal to $1.42 \cdot 10^{3}[\mathrm{~Pa} \cdot \mathrm{s}]^{-1}$. The experiment was performed at $55^{\circ} \mathrm{C}$, at which the water viscosity is around $0.50 \mathrm{mPa}$ s (Kestin et al. (Kestin et al., 1978)). Therefore the mobility for water, which is the displaced fluid, is $1 / \mu_{w}=2.0 \cdot 10^{3}[\mathrm{~Pa} \cdot \mathrm{s}]^{-1}$. This means that the mobility of the leading edge of the foam bank is slightly lower than that of the water: $\lambda_{r t \text { foam }} / \lambda_{r t \text { water }}=0.71$. Thus, the results indicate that, even though the foam is rather weak (i.e. has low apparent viscosity), it is still able to maintain mobility control over the displaced water phase. This finding agrees with previous studies (e.g. Khatib et al. (1988)) who found reduced foam strength in lower-permeability porous media. This result is similar to the 'weak foam' proposed by Boeije and Rossen (2015b). Foam like this has the advantage that the injectivity is relatively high, so a foam-injection process can be carried out in a shorter time. If used in the field, the resulting foam front may show some instabilities which could lead to lower sweep efficiency, as was shown in simulation studies by Boeije and Rossen (2015b) and Farajzadeh et al. (Farajzadeh et al., 2016).

The fit through the pressure-gradient data of the APG experiment using the model parameters in Fig. 5 is shown in Fig. 6 . Note that the transitional foam quality $\left(f_{g}^{*}\right)$ is rather low for this set of parameters (around 0.25 ). This is a result of the chosen value of fmmob. If a different value of fmmob were chosen, the transitional foam quality would shift left or right, but the straight-line fit through the data points in the high-quality regime would remain the same.

We performed the same set of experiments using the same foam qualities with the AES surfactant. Fig. 7 shows the pressure-gradient data as a function of foam quality. Apart from the lowest foam quality investigated $\left(f_{g}=0.5\right)$, all of the data points are in the high-quality

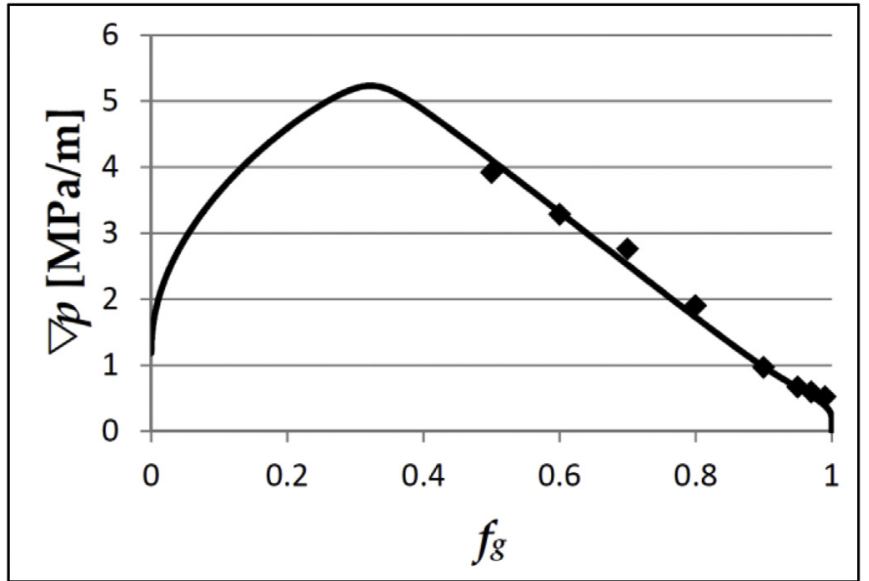

Fig. 6. Steady state $f_{g}$ vs. $\nabla p$ data for the experiment using the APG surfactant along with STARS model fit using the following parameter values: fmmob $=20$, fmdry $=0.59 \pm 0.01$, epdry $=600$.

regime. The straight line fit shown in the figure gives a first estimate of the behaviour in this regime.

The resulting water saturations are calculated using the same water relative-permeability function as before (i.e. Eq. (3)) and are shown as fractional-flow data in Fig. 8a. A more detailed close-up of the same fractional-flow data is shown in Fig. 8b. Water fractional flow is not a monotonically increasing function of the water saturation. This result is similar to that of Wassmuth et al. (Wassmuth et al., 2001), Kibodeaux

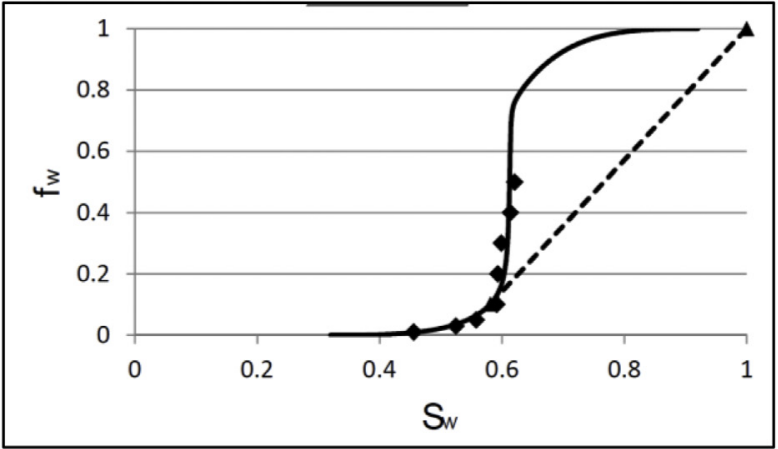

(a)

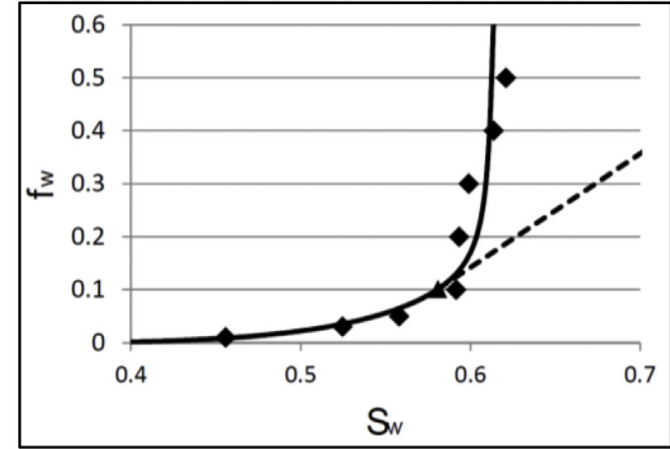

(b)

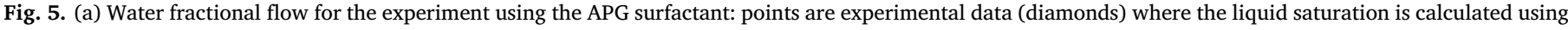

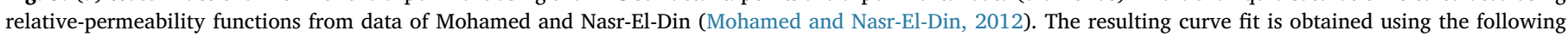

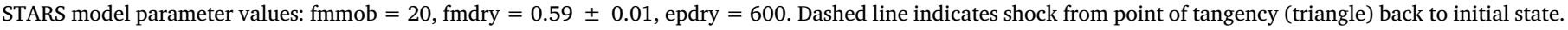
(b) detailed view of the same fractional-flow curve around the point of tangency. 


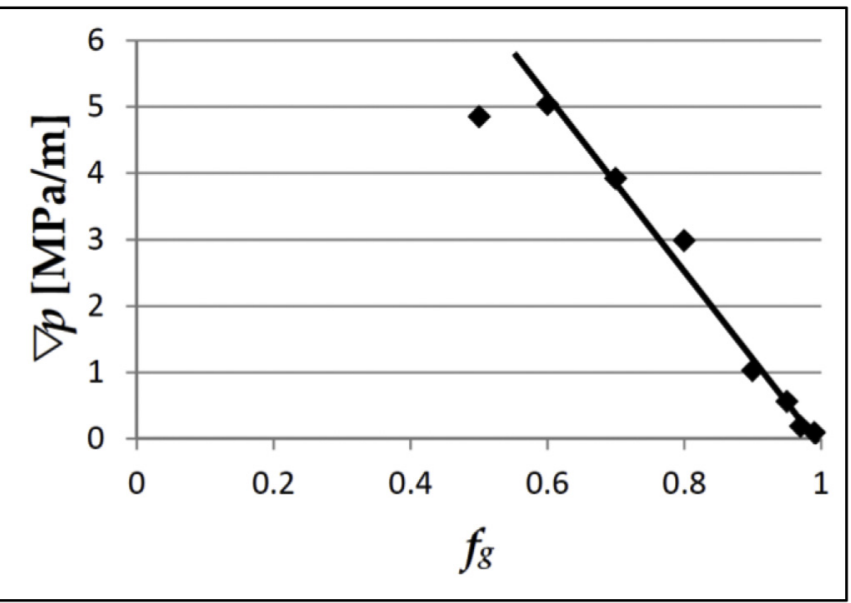

Fig. 7. Steady state pressure gradient $\nabla p$ over the middle section of the core for the experiment using the AES surfactant as a function of foam quality $\left(\mathrm{f}_{\mathrm{g}}\right)$. All data points except the lowest foam quality studied $\left(f_{g}=0.5\right)$ are clearly in the high-quality regime. Straight line fit is first estimate and is used to determine limiting water saturation $\mathrm{S}_{\mathrm{w}}{ }^{*}$.

and Rossen (1997) and Xu and Rossen (2004). Rossen and Bruining (2007) argue that this kind of fractional-flow curve could represent a combination of two different curves, one for strong and one for weak foam. It is also possible that the large scatter in $S_{w}$ values in Fig. $8 \mathrm{~b}$ may be the result of experimental uncertainty. However, to bring the datum of $S_{w}=0.62$ (at $f_{g}=0.97$ ) down to $S_{w}=0.57$, the measured pressure drop would have to be around 0.32 bar rather than the 0.21 bar that was measured. This is an increase of approximately $50 \%$, which is beyond the expected uncertainty in our pressure measurements.

According to Rossen and Bruining (2007), in such a case the shock goes to the weak-foam part of the fractional flow curve, directly below the lowest- $S_{w}$ datum of the strong-foam part of the curve, as shown in Fig. 9. The result is a high-mobility foam bank behind the shock, not capable of maintaining mobility control at the front. Our fitting approach is only suitable for fractional flow curves where the value of $f_{w}$ increases monotonically with increasing water saturation, which is not the case for this data-set and therefore we cannot fit the results from this experiment.

\subsection{The effect of oil}

To determine the effect of oil on the foaming performance of both surfactants we performed an experiment where we added crude oil $\left(32^{\circ} \mathrm{API}\right)$ to the co-injection process. The foam quality in this experiment was kept constant at $f_{g}=0.5$. Without oil we managed to get a

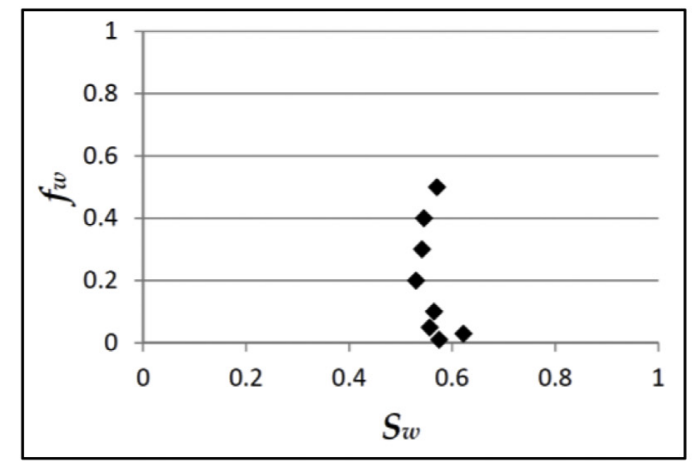

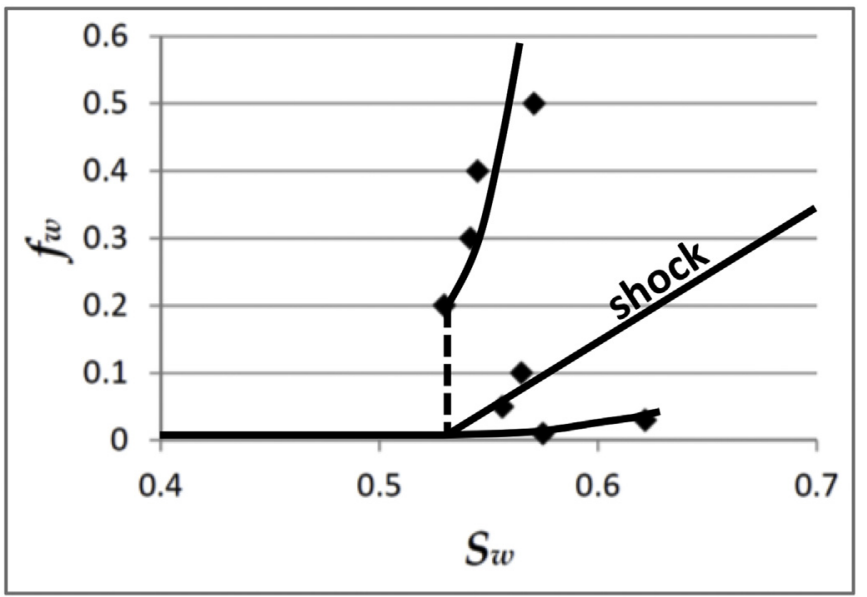

Fig. 9. Construction of shock formed upon gas injection in SAG using the data from the experiment with AES surfactant and the method of Rossen and Bruining (2007).

fairly strong foam at this foam quality with both surfactants (cf. Figs. 4 and 6) so if there is any effect of the oil we should be able to clearly see it from a lower pressure gradient over the core. We maintained the same injection rates of gas and surfactant solution that we also used in the previous experiment (i.e. $0.05 \mathrm{ml} / \mathrm{min}=6.63 \cdot 10^{-7} \mathrm{~m} / \mathrm{s}$ ) and then we added the crude oil to the injection process. We do not include oil flow rate in the definition of foam quality. The oil flow rate used in these experiment is one quarter of the water flow rate and since we use a foam quality of 0.5 this is also equal to one quarter of the gas solution flow rate $\left(Q_{o}=Q_{g} / 4=Q_{w} / 4\right)$. We first generated a foam in the core without oil and then started oil injection to see its effect on the pressure gradient. Figs. 10 and 11 show the resulting pressure-gradient profiles for the APG and the AES experiment respectively. Both experiments were carried out at a salinity of $200,000 \mathrm{ppm}$. These plots comprise both the injection process without oil until a steady state is reached and the subsequent process where oil is co-injected along with the other fluids. The pressure gradient without oil is somewhat lower (3.0 vs. 3.9 and $4.8 \mathrm{MPa} / \mathrm{m}$ ) than it was in the previous experiments even though the experimental conditions were the same. This difference could be the result of a change in the permeability of the core. For each surfactant, the same core was used for the initial experiments without oil and this experiment with oil. Prolonged periods of liquid injection may have led to dissolution thereby affecting the permeability. It is also possible that some pollutants entered the system (e.g. impurities in the surfactant solution) which may have had a modest detrimental effect on the foaming performance.

Initially after the start of the oil injection (around $t=14,000 \mathrm{~s}$ for

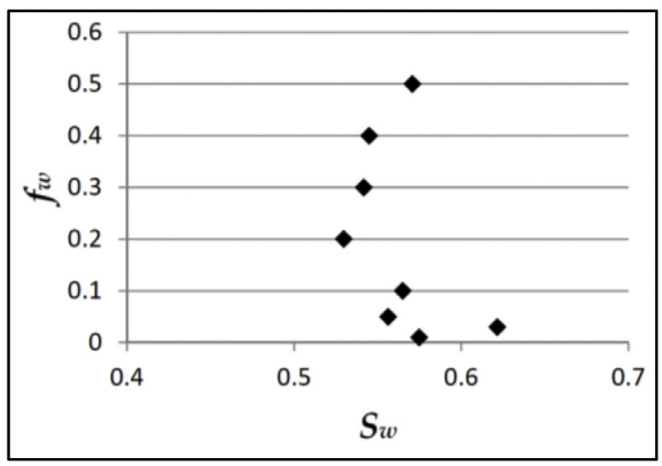

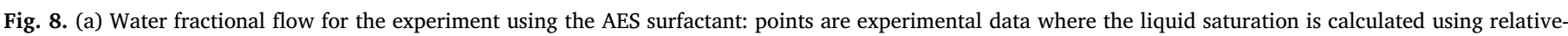

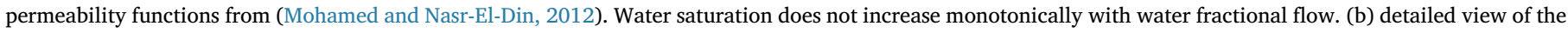
same experimental data, more clearly showing the non-monotonicity in the fractional-flow curve. 


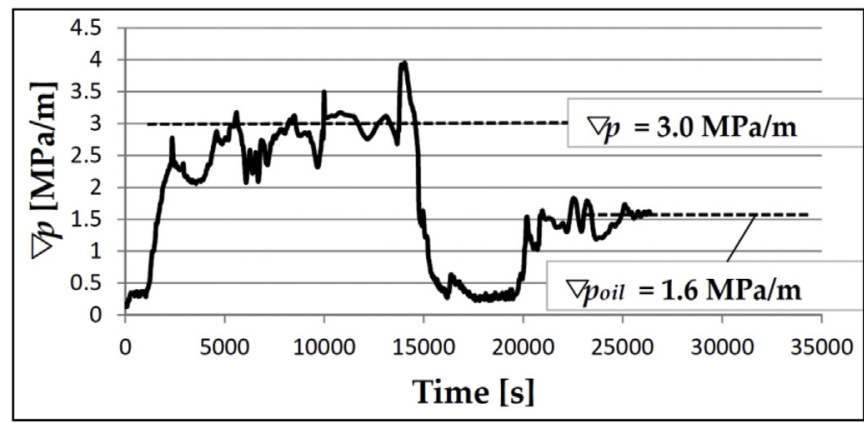

Fig. 10. Pressure-gradient results from the experiment with the APG surfactant when oil is added to the injection process. Steady state without foam is reached around $\mathrm{t}=14,000 \mathrm{~s}$, after which oil injection is started; oil reaches the core shortly thereafter.

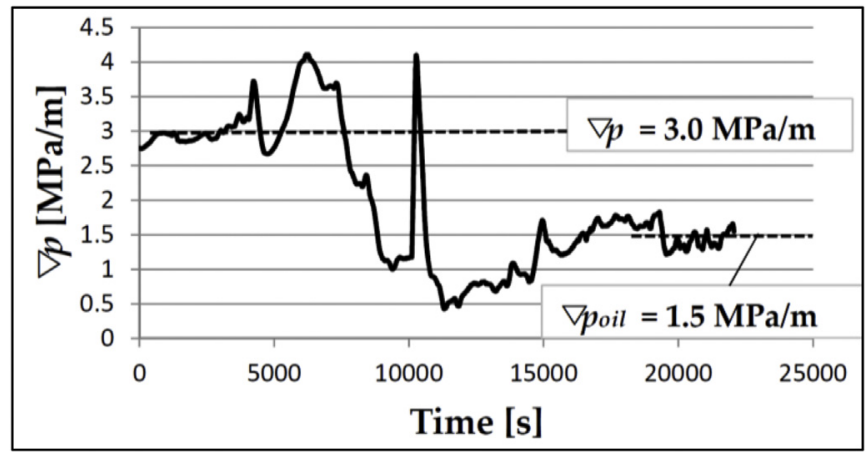

Fig. 11. Pressure-gradient results from the experiment with the AES surfactant when oil is added to the injection process. Steady state without foam is reached around $\mathrm{t}=5000 \mathrm{~s}$, after which oil injection is started; oil reaches the core shortly thereafter.

the APG case and $t=5000 \mathrm{~s}$ for the AES case) the pressure drop initially rises slightly. This is a result of the start of the oil injection. The overall flow rate is increased because of this, but the oil has not yet reached the core and thus does not affect the foaming performance just yet.

Further observations show that both surfactants perform similarly. The maximum pressure gradient without oil is $3.0 \mathrm{MPa} / \mathrm{m}$ for both surfactants. Then when oil is added there is a short rise in the pressure gradient, because the oil has not yet reached the core, but the injection rate increases slightly. This is then followed by an abrupt decline in pressure gradient, implying oil is destroying the foam almost completely. However, after this initial decline, a gradual increase in pressure gradient occurs, meaning that some mobility reduction is again taking place. With oil, the steady-state pressure gradient is roughly halved, compared to the injection process without oil, for both surfactants $(\nabla p=1.6$ and 1.5 vs. $3.0 \mathrm{MPa} / \mathrm{m})$.

We examined the foam structure qualitatively at the outlet of the core. We use RADEL tubing for our fluid lines, which can be used at high pressure, but is still transparent, allowing "by eye" observations of the fluids inside. From our qualitative observations we find that the fluids at the outlet of the core were more like an emulsion than a foam. A representative example of the observations is shown in Fig. 12, which shows the fluids inside the RADEL tubing. Overall we find that foaming in the presence of oil is challenging in these rocks, but that some mobility reduction can still be achieved.

\subsection{CT experiments}

CT scans depend on attenuation coefficients, which are different for every material. The original attenuation coefficients are commonly transformed into Hounsfield units (also known as CT numbers) using a linear transformation. Hence one can use these to distinguish the liquid

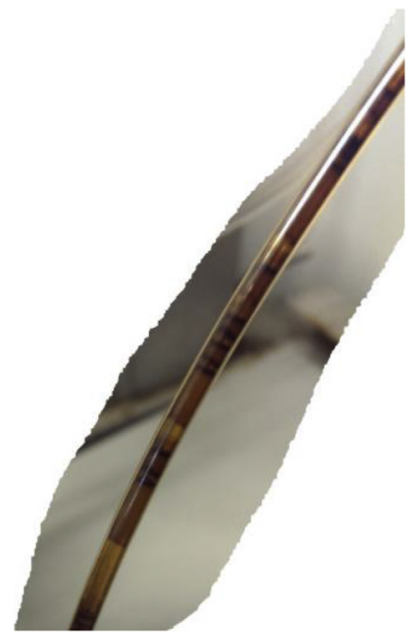

Fig. 12. Fluids at the outlet of the core; appearing more like an emulsion than a foam.

(aqueous surfactant solution; no oil), gas and the rock itself. To calculate rock porosity and fluid saturations inside the core we make use of the method outlined in detail in Rangel-German et al. (Rangel-German et al., 1999). Here we only mention the parts of their method relevant to our study (i.e. limited to two-phase flow), but we use the same nomenclature as in their study. First we calculate the rock's porosity by comparing attenuation coefficients of a dry core with one that is fully saturated with liquid:

$\phi=\frac{C T_{c w}-C T_{c d}}{C T_{w}-C T_{a}}$

where $C T_{c w}$ is the CT number for the rock at a matrix location that is fully saturated with liquid. $C T_{c d}$ is the CT number for a dry core at a matrix location. Both $C T_{c w}$ and $C T_{c d}$ may vary for every pixel in the CT image of the core. $C T_{w}$ is the CT number for the liquid (water). Since we do not use any salinity in the liquid solution, $C T_{w}$ is close to 0 for this study. $C T_{a}$ is the CT number for air, which is about -1000 . For twophase, gas-liquid systems, the liquid saturation inside the core can be calculated as follows:

$S_{w}=\frac{C T_{a w}-C T_{c d}}{C T_{c w}-C T_{c d}}$

where $C T_{a w}$ is the CT number for the core saturated with both liquid and gas. This is the CT number we obtain from the scans that are taken during the foam flooding experiments. Fig. 13a shows a vertical scan through a core ( $17 \mathrm{~cm}$ in length and $4 \mathrm{~cm}$ in diameter) at vacuum. This scan clearly shows multiple distinct vugs that are several $\mathrm{mm}$ in size. These vugs appear as black spots on the scan, because of their lower attenuation coefficient. The resulting porosity map for the core is shown in Fig. 13b and c. The vugs have porosity equal to 1 . Therefore, these dominate the porosity map and it is hard to distinguish details in the regions with lower porosity. Therefore, we plot the porosity figure again with the color axis clipped so every porosity value higher than 0.3 is shown as full scale.

We measured both the liquid permeability and the porosity of this rock in similar fashion to the previous set of experiments; on average the permeability is around $0.5 \mathrm{mD}$ and the porosity is 0.2 . The foam floods in this experiment are all carried out using a very high foam quality $f_{g}=0.99$ and total superficial velocity of $5.31 \cdot 10^{-7} \mathrm{~m} / \mathrm{s}$. This quality was chosen because the low permeability $(0.5 \mathrm{mD})$ means that large pressure gradients are expected. Also, the absence of salts in the surfactant solution and carrying out the experiment at ambient temperature means that a fairly strong foam can be generated, leading to even higher pressure gradients. Since we aim only to visualize the influence of heterogeneities, this limitation of the foam quality is 

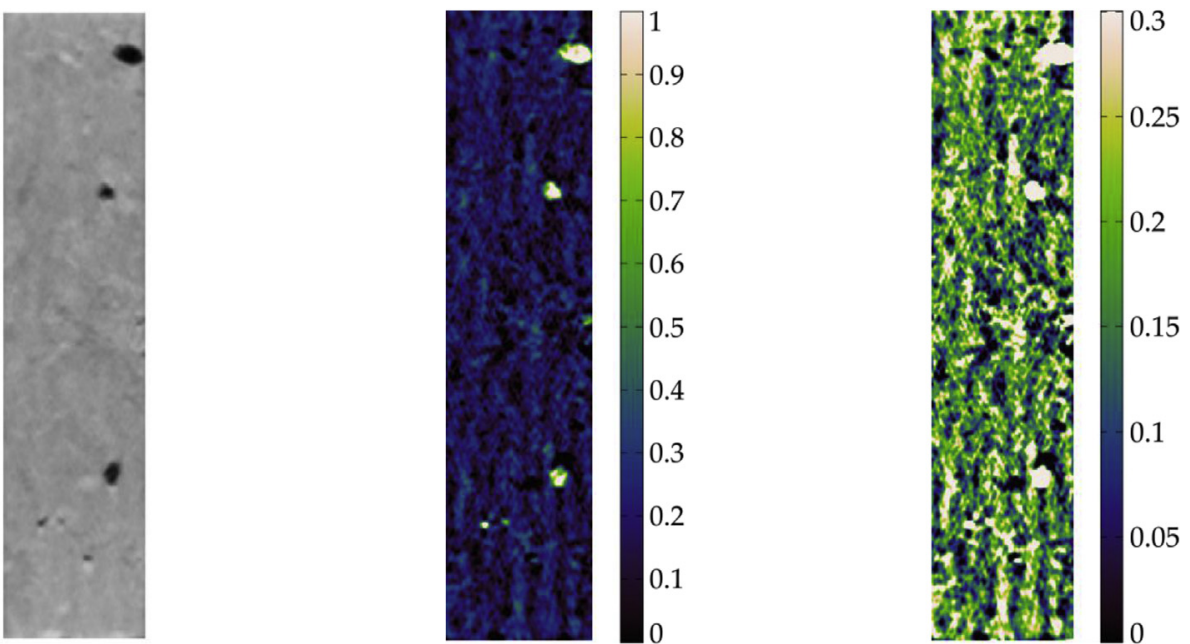

Fig. 13. (a) CT scan of Edwards White core, showing several vugs several mm in size, (b) Porosity $\phi$ shown with a range of $0-1$ indicating high porosity in the vugs, (c) Porosity $\phi$ shown with a range of 0-0.3 indicating other heterogeneities are present besides the vugs.

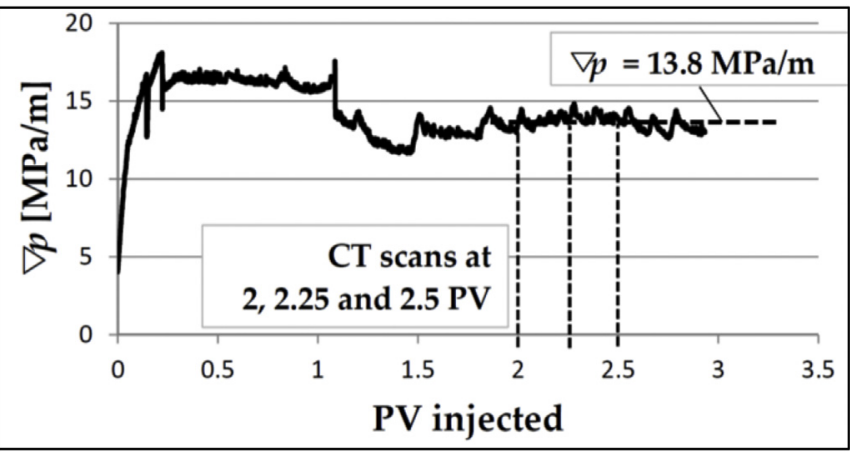

Fig. 14. Pressure gradient over the entire Edwards White core in the CT visualization experiment $\left(u_{t}=5.31 \cdot 10^{-7} \mathrm{~m} / \mathrm{s}, f_{g}=0.99\right)$.

acceptable. Pressure-gradient results from this experiment are shown in Fig. 14. We applied this relatively low superficial velocity in order to maintain a pressure drop over the core within the range of the transducer and also to avoid damaging the core. As can be seen from the graph, the maximum observed pressure gradient is roughly $18 \mathrm{MPa} / \mathrm{m}$, which for a $17 \mathrm{~cm}$ core equates to a 30 bar pressure drop. This also means that there is some ambiguity in the terms Pore Volume (PV) and foam quality, because these are defined with respect to the 100 bar back pressure.

The figure also shows that, at least in terms of pressure gradient, a steady state is achieved in this core. There are still some observable pressure fluctuations after $2 \mathrm{PV}$ of fluids has been injected, but these fluctuations are not significantly larger than those found in previous experiments using the more homogeneous Indiana Limestone cores. This implies that the rock heterogeneities, such as the vugs, do not cause large fluctuations in the pressure response on a macro-scale. The resulting steady-state pressure gradient is approximately $13.8 \mathrm{MPa} / \mathrm{m}$. Under these conditions, this is equivalent to a mobility reduction factor $(M R F)$ of around 12.8 compared to the mobility of water. So even at very high foam quality it is still possible to generate fairly strong foam in this rock. The observed mobility reduction factor is also significantly higher than that in the previous set of experiments using the Indiana Limestone cores, even though those were performed in higher-permeability rock. This implies that the salinity and the elevated temperature used in that experiment have a significant impact on foaming performance. As mentioned, the experiment was limited to very high foam quality. An attempt was made to carry out measurements at lower foam quality $\left(f_{g}=0.8\right)$, but the generated foam was too strong, resulting in excessive build-up of pressure. Even when we lowered the flow rate further to the minimum accessible value of the equipment, the resulting pressure gradients exceeded the transducer range and thus this experiment was terminated.

\subsection{CT scans during experiment}

In total, five CT scans were made of the core during the foamflooding experiment with $f_{g}=0.99$. All of the scans were taken with the core at steady state in terms of pressure gradient. The first three CT scans were taken, as indicated in Fig. 14, after 2, 2.25 and 2.5 PV of fluid injection respectively. After these three scans, we tried the aforementioned experiment with $f_{g}=0.8$ which was terminated due to excessive pressure build-up. Afterwards the high foam quality of $f_{g}=0.99$ was resumed and two more scans were taken once steady state had been reached once more. The latter two scans were taken to determine the reproducibility of the results.

By combining the CT results during the experiment with scans of a dry core and a core fully saturated with surfactant solution we can convert the resulting scans into liquid-saturation maps using Eq. (8). We analyze the results in three different ways. First we look at the average liquid saturation at every vertical position inside the core. That is, we take the arithmetic average of every horizontal line of saturation voxels and use the result as a measure of the variation in saturation throughout the core. Next, we look at the complete, non-averaged, data to see how the heterogeneities affect the saturations in the foam on the core scale. Finally, we focus on the saturations in the vugs and see how the fluids are distributed there and how this distribution changes with time.

The resulting average saturation profiles as a function of the height of the core from this experiment are shown in Fig. 15a and b. The former shows just the saturation profile from the first scan (at $2 \mathrm{PV}$ injected). This shows a relatively constant saturation of $S_{w}=0.37$ throughout the core, although there are some minor fluctuations from this number. The only place where the liquid saturation changes drastically is towards the outlet of the core. This could be caused by the capillary end effect, which causes liquid hold-up towards the core's outlet. The fluctuations in the saturation that are observed also do no coincide with the axial location of the vugs: thus at a core scale the vugs do not seem to have a great effect on the average saturation. Fig. 15b shows the combined average saturation profile from all the CT scans. This shows there is only minor variation in the saturation in time, indicating that a steady state is reached and is not affected greatly by the heterogeneities in the rock. 


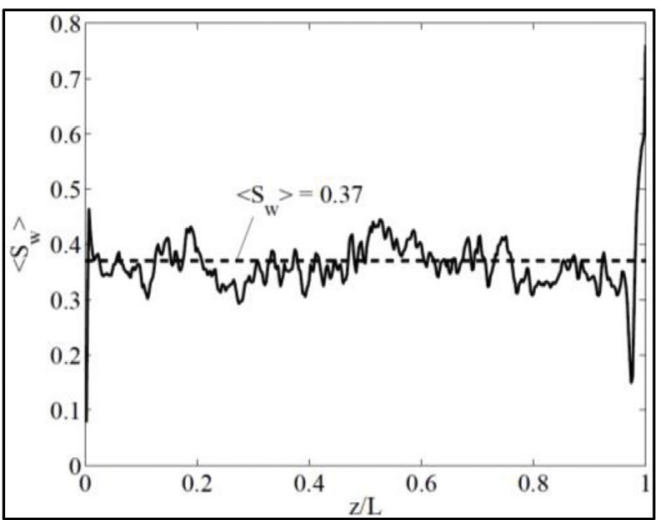

(a)

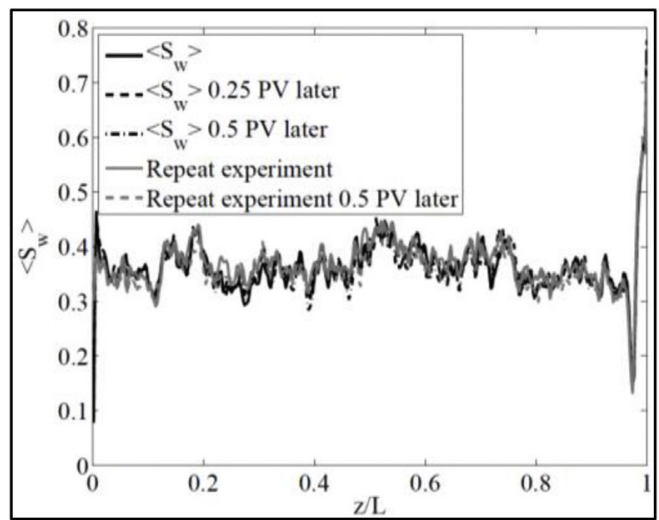

(b)

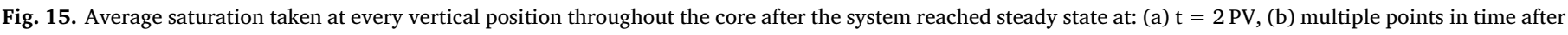
state (a).

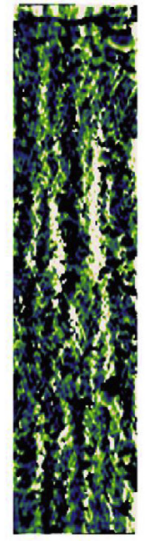

(a)

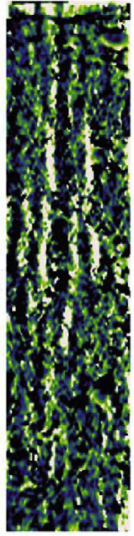

(b)

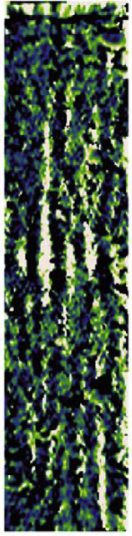

(c)

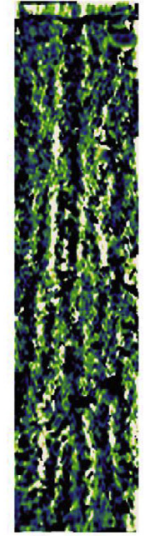

(d)

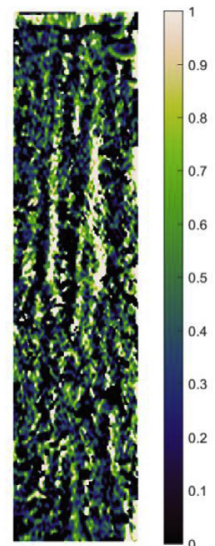

(e)

Fig. 16. Liquid saturation $\left(\mathrm{S}_{\mathrm{w}}\right)$ throughout the core taken at different points in time for experiment with $f_{g}=0.99$. Scan (a) was taken when steady state was reached (at $2 \mathrm{PV}$ injected). Scan (b) and (c) were respectively taken 0.25 PV and 0.5 PV later. Scan (d) was taken after steady state had been reached in the repeat experiment. Scan (e) was taken 0.5 PV after scan (d). Data were not averaged in any way.

Based on the average-saturation profiles, we might conclude that the rock heterogeneities have no effect on the saturation inside the core, since the resulting average all appear to be constant throughout the core and also steady in time. However, a look at the complete nonaveraged CT scans, as shown in Fig. 16a through e, shows that on the core scale large variations in saturation are found. These figures show the five complete, non-averaged, saturation profiles. These are the profiles used as input data in the average profiles discussed above. Broad features are consistent among the scans, but there is also substantial fluctuation in saturation on the fine scale from image to image. This suggests either scatter in the CT images or fluctuation in saturation on the fine scale. The core needs to be analyzed in greater detail to fully explain these large fluctuations in saturation (e.g. through $\mu \mathrm{CT}$ imaging).

Finally we focus on the flow behaviour inside the vugs. As shown in the scan of the dry core (Figure 13a), there are three large vugs several $\mathrm{mm}$ in size along the right-hand side of Fig. 13a and b. Fig. 17a to c show the saturation profiles in the vugs indicated on the leftmost figure. The second figure from the left shows a detailed view of the given vug. The second figure from the right shows the saturation profile in the vug from the first scan that is taken and the rightmost figure shows the result of the last scan. The resulting saturation profile remains constant through time for each of the vugs indicating that a steady state is reached. We find that two regions can be distinguished within each vug: one filled with liquid and the other filled with gas. The latter is located slightly above the liquid region. There is scatter in the images, both inside and outside the vugs, but in all six images water saturation is distinctly greater near the bottom of the vug. There is a clear boundary separating the two regions which remains stable through time (that is, it is in the same location in the last scan as in the first). This implies that foam is segregating inside the vugs, but the effect of the vugs appears to be limited to the vugs itself. Directly outside the vugs we can already see changes in saturation (green colors in the saturation profiles) which implies foam is present there.

\section{Conclusions}

The long-core experiments show that foam EOR is possible in lowpermeability carbonate rocks. However, foam strength is considerably reduced compared to previous experiments we conducted in high-permeability unconsolidated bead-packs. The two different surfactants we tested here show similar foam strength, but the experiment with the AES surfactant shows indications of multiple steady states at very high foam qualities. As a result of this, our fitting approach to determine whether this surfactant is suitable for a SAG foam application cannot be applied accurately to that case, because we do not know where to place the shock on the fractional-flow curve. For the experiment using the APG experiment we did not find these multiple steady states during the experiments, so for this experiment we can use our fitting approach. We find that at the leading edge of a foam front in a gas-injection cycle of a SAG process, this foam is just able to maintain mobility control over the displaced phase. When crude oil is added to the injection process, the foam strength is reduced. In our experiments we found that the resulting steady-state pressure gradient is roughly halved in the presence of oil. Also we observed that the fluids at the outlet appear more like an emulsion than a foam. Still, some mobility reduction can be achieved 

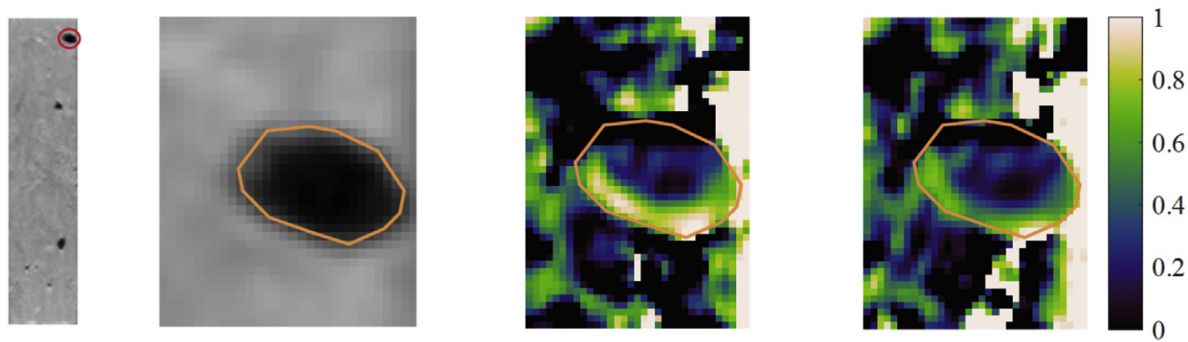

(a)
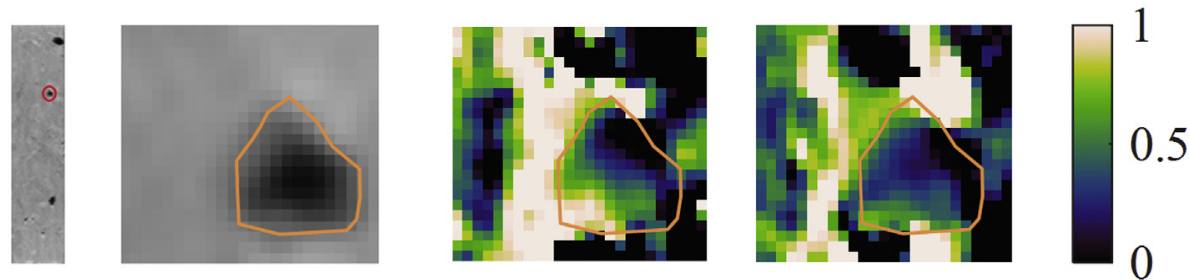

(b)
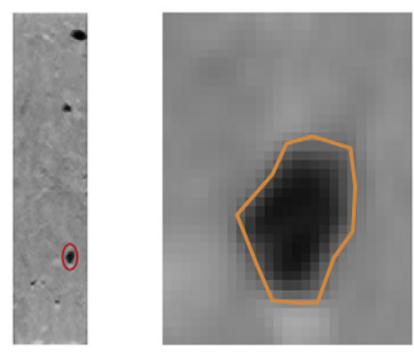

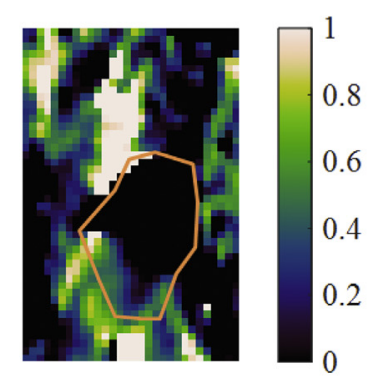

Fig. 17. Liquid saturation $\left(S_{\mathrm{w}}\right)$ inside the largest major vugs. Left figure of dry core indicates the vug of which the saturation profile is shown. Second figure from the left shows detailed view of the vug. Second figure from the right shows profile from the first scan that is taken. Rightmost figure shows the profile of the last scan that is taken. Profiles show separate regions for liquid (white color in the profile) and gas (black) in the vugs with gas being on top of the liquid. The boundary between the wetter and drier regions remains at roughly the same location throughout the experiment. (For interpretation of the references to color in this figure legend, the reader is referred to the Web version of this article.)

(c)

with crude oil flowing along with the foam.

CT visualization experiments in heterogeneous, vuggy rocks show that foaming is also possible in these rocks. Based on average saturation profiles we conclude that the influence of isolated vugs is limited. Average saturation (on a scale of $\mathrm{cm}$ ) is fairly uniform throughout the core, indicating that there is foam present. The detailed, non-averaged saturation profiles of the entire core show more-chaotic behaviour than the average values. At steady state, regions of high and low liquid saturation are present very close to each other. This might be the result of layering in the heterogeneous core. The influence of the vugs does not prevent the generation of foam on the core scale. We find that there are two distinct regions inside the vugs. The bottom part is filled with liquid whereas the remainder is full of gas. This implies that foam segregation occurs in the vugs, but this effect is limited to the vugs. Foam still exists in the remainder of the core.

\section{Acknowledgements}

We gratefully acknowledge the financial support of Maersk Oil, especially helpful discussions with Dr. M. Vad Bennetzen.

\section{References}

Alvarez, J.M., Rivas, H.J., Rossen, W.R., 2001. Unified model for steady-state foam behavior at high and low foam qualities. SPE J. 6 (3), 325-333.

Bernard, G.G., Holm, L.W., 1964. Effect of foam on permeability of porous media to gas. Soc. Petrol. Eng. J. 4, 267-274.

Boeije, C.S., Rossen, W.R., 2015a. Fitting foam-simulation-model parameters to data: I. Coinjection of gas and liquid. SPE Reservoir Eval. Eng. 18 (02), 264-272 (SPE 174544).

Boeije, C.S., Rossen, W.R., 2015b. Gas-injection rate needed for SAG foam processes to overcome gravity override. SPE J. 20 (01), 49-59.

Boeije, C.S., Bennetzen, M.V., Rossen, W.R., 2017. A methodology for screening surfactants for foam enhanced oil recovery in an oil-wet reservoir. SPE Reservoir Eval. Eng. 20 (4).

Computer Modeling Group. STARS User's Guide, Calgary, Alberta, Canada.
Ehrenberg, S.N., Nadeau, P.H., 2005. Sandstone vs. carbonate petroleum reservoirs: a global perspective on porosity-depth and porosity-permeability relationships. AAPG (Am. Assoc. Pet. Geol.) Bull. 89, 435-445.

Ettinger, R.A., Radke, C.J., 1992. Influence of texture on steady foam flow in Berea sandstone. SPE Reservoir Eng. 7 (01), 83-90.

Falls, A.H., Hirasaki, G.J., Patzek, T.W., Gauglitz, D.A., Miller, D.D., Ratulowski, J., 1988. Development of a mechanistic foam simulator: the population Balance and generation by snap-off. SPE Reservoir Eng. 3, 884-892.

Farajzadeh, R.;A.,E.A., Kahrobaei, S., Hajibeygi, H., Van der Meer, J.M., Vincent-Bonnieu, S., Rossen, W.R., 2016. Simulation of instabilities and fingering in surfactant alternating gas (SAG) foam enhanced oil recovery. J. Nat. Gas Sci. Eng.

Fern $\varnothing$, M.A., Eide, Ø., Steinsb $\emptyset$, M., Langlo, S.A.W., Christophersen, A., Skibenes, A., Ydsteb $\emptyset$, T., Graue, A., 2015. Mobility control during CO2 EOR in fractured carbonates using foam: laboratory evaluation and numerical simulations. J. Petrol. Sci. Eng. 135, 442-451.

Kapetas, L., Bonnieu, S.V., Danelis, S., Rossen, W.R., Farajzadeh, R., Eftekhari, A.A., Shafian, S.R.M., Bahrim, R.Z.K., 2016. Effect of temperature on foam flow in porous media. J. Ind. Eng. Chem. 36, 229-237.

Kestin, J., Sokolov, M., Wakeham, W.A., 1978. Viscosity of liquid water in the range -8 degC to 150 degC. J. Phys. Chem. Ref. Data 7 (3), 941-948.

Khatib, Z.I., Hirasaki, G.J., Falls, A.H., 1988. Effects of capillary pressure on coalescence and phase mobilities in foams flowing through porous media. SPE Reservoir Eng. 3, 919-926.

Kibodeaux, K.R., Rossen, W.R., 1997. Coreflood Study of Surfactant-alternating-gas Foam Processes: Implications for Field Design. SPE Western Regional Meeting (SPE 38318).

Lake, L.W., Johns, R.T., Pope, G.A., Rossen, W.R., 2014. Fundamentals of Enhanced Oil Recovery. Society of Petroleum Engineers.

Ma, K., Lopez-Salinas, J.L., Puerto, M.C., Miller, C.A., Biswal, S.L., Hirasaki, G.J., 2013. Estimation of parameters for the simulation of foam flow through porous media. Part 1: the dry-out effect. Energy Fuels 27 (5), 2363-2375.

Mohamed, I.M., Nasr-El-Din, H.A., 2012. Formation damage due to CO2 sequestration in deep saline carbonate aquifers. SPE International Symposium and Exhibition on Formation Damage Control (SPE 151142).

Moradi-Araghi, A., Johnston, E.L., Zomes, D.R., Harpole, K.J., 1997. Laboratory evaluation of surfactants for CO2-foam applications at the south cowden unit. SPE International Symposium on Oilfield Chemistry (SPE 37218).

Rangel-German, E., Akin, S., Castanier, L., 1999. Multiphase-flow Properties of Fractured Porous Media. SPE Western Regional Meeting (SPE 54591).

Ransohoff, T.C., Radke, C.J., 1988. Mechanisms of foam generation in glass-Bead packs. SPE Reservoir Eng. 3, 573-585.

Rossen, W.R., Boeije, C.S., 2015. Fitting foam-simulation-model parameters to data: II. Surfactant-Alternating-Gas foam applications. SPE Reservoir Eval. Eng. 18 (02), 273 283-283. 
Rossen, W.R., Bruining, J., 2007. Foam displacements with multiple steady states. SPE J. $12,5-18$.

Rossen, W.R., 1996. Foams in enhanced oil recovery. In: Prud'homme, R.K., Khan, S. (Eds.), Foams: Theory, Measurements and Applications. Marcel Dekker, New York, pp. 413-464 Prud'homme, R. K.; Khan, S.

Schramm, L.L., 1994. Foams: Fundamentals and Applications in the Petroleum Industry. American Chemical Society, Washington, DC, USA.

Shan, D., Rossen, W.R., 2004. Optimal injection strategies for foam IOR. SPE J. 9 (2),
$132-150$.

Szlendak, S.M., Nguyen, N., Nguyen, Q.P., 2012. Successful Laboratory Investigation of Low-tension-gas (LTG) Flooding for Tertiary Oil Recovery in Tight Formations ( $\sim 10 \mathrm{mD}$ to Gas). SPE Annual Technical Conference and Exhibition (SPE 159841). Wassmuth, F.R., Green, K.A., Randall, L., 2001. Details of in-situ foam propagation exposed with magnetic resonance imaging. SPE Reservoir Eval. Eng. 4, 135-145.

Xu, Q., Rossen, W.R., 2004. Experimental study of gas injection in surfactant-alternatinggas foam process. SPE Reservoir Eval. Eng. 7, 438-448. 